\title{
Psychometric evaluation of the Polish version of the Adherence to Refills and Medications Scale (ARMS) in adults with hypertension
}

\author{
Katarzyna Lomper' \\ Mariusz Chabowski ${ }^{2}$ \\ Anna Chudiak' \\ Artur Białoszewski ${ }^{3}$ \\ Krzysztof Dudek ${ }^{4}$ \\ Beata Jankowska-Polańska' \\ 'Division of Nursing of Internal \\ Diseases, Department of Clinical \\ Nursing, Faculty of Health Science, \\ Wrocław Medical University, \\ Wrocław, Poland; ${ }^{2}$ Division of \\ Surgical Procedures, Department of \\ Clinical Nursing, Faculty of Health \\ Science, Wrocław Medical University, \\ Wrocław, Poland; ${ }^{3}$ Department of \\ Prevention of Environmental Hazards \\ and Allergology, Warsaw Medical \\ University, Warsaw, Poland; ${ }^{4}$ Faculty \\ of Mechanical Engineering, Wrocław \\ University of Science and Technology, \\ Wrocław, Poland
}

This article was published in the following Dove Press journal: Patient Preference and Adherence

\begin{abstract}
Background: Only $50 \%-75 \%$ of chronically ill patients take their medication as prescribed. The patient is found to adhere to treatment correctly and optimally if they accomplish $80 \%$ or more of the treatment plan. A questionnaire titled the Adherence to Refills and Medications Scale (ARMS) has been used in studies involving various populations and proved to be a simple instrument for measuring adherence, with good psychometric properties.
\end{abstract}

Objective: The aim of this study was to develop a Polish version of the ARMS (ARMS-P), an instrument that identifies levels of adherence in the hypertensive population, and evaluate its psychometric properties.

Methods: This cross-sectional study included 279 patients, including 166 females (mean age 66.5 years), hospitalized between September 2016 and March 2017 in the Department of Internal Medicine, Occupational Diseases, and Hypertension of Wrocław Medical University, Poland. The 12-item ARMS was translated from English into Polish. The 12 items included in the final questionnaire comprise two subscales: adherence to taking medications (eight items) and adherence to refilling prescriptions (four items).

Results: Patients in the good-adherence group were younger ( $P=0.017 ; P=0.048)$, more likely to be professionally active ( $P=0.041)$, better educated $(P=0.037)$, and more likely to have normal blood pressure $(P<0.001)$. They also measured their blood pressure more often $(P<0.001)$, and took fewer pills in a day $(P<0.001)$. Adherent patients were also more likely to take their medication on their own $(P=0.016)$ and read information leaflets on the medication $(P<0.001)$. The study demonstrated that the ARMS-P questionnaire has good psychometric properties that enable its use for assessing adherence in chronically ill patients, including in particular, patients with hypertension.

Conclusion: The psychometric properties of the questionnaire are satisfactory (reliability measured by means of Cronbach's $\alpha$ ). The ARMS-P questionnaire proved to be suitable for use in the Polish population. The use of this screening tool for the assessment of adherence to treatment is recommended in this population of hypertensive patients.

Keywords: adherence, 12-item ARMS, questionnaire, hypertension

\section{Introduction}

As reported in the literature, as little as $50 \%-75 \%$ of chronically ill patients take their medication as prescribed. ${ }^{1}$ Nonadherence to treatment may pose a serious medical, social, and economic problem. If a patient does not adhere to their treatment plan, they may not achieve the expected outcomes. ${ }^{2}$ Adherence to treatment is understood as the patient's informed and voluntary involvement in the acceptabletreatment process. Adherence comprises three aspects: initiation, implementation, and
Correspondence: Mariusz Chabowski Department of Surgery, Fourth Military Teaching Hospital, 5 Weigla Street, Wrocław 50-98I, Poland

Tel +48 261660247

Fax +4826I660245

Email mariusz.chabowski@gmail.com 
discontinuation/persistence. ${ }^{3}$ According to the literature, an arbitrary cutoff point of $80 \%$ for cooperating patients has been adopted. ${ }^{4}$

Nonadherence to the prescribed pharmaceutical treatment may be associated with a number of factors, including in particular the frequency of taking the medication, its side effects, the complexity of the treatment process, and economic factors. Other reported predictors of adherence include psychological health issues, cognitive impairment, lack of conviction as to the purpose and effectiveness of treatment, and poor relationships between patients and health care professionals..$^{5}$ A study found that self-reported medication nonadherence was associated with a doubling of subsequent cardiovascular events. ${ }^{6}$

Despite significant advances in hypertension treatment made in the last decade, hypertension remains the number one public health issue: ${ }^{2} 54 \%$ of strokes and $47 \%$ of cardiac deaths are attributed to suboptimal blood pressure (BP) control. Epidemiological studies demonstrate that in Poland, approximately $29 \%$ of adults are diagnosed with hypertension, but only $12 \%$ of these patients are treated correctly. ${ }^{7}$ Moreover, the effectiveness of hypotensive treatment has been estimated at 5\%-15\%. ${ }^{8}$ The available studies show that $50 \%$ of hypertensive patients discontinue treatment within 12 months of its beginning. Another 30\% continue treatment, but do not comply fully with the prescribed protocol. Insufficient adherence is the primary contributor to unsatisfactory response to pharmaceutical treatment. ${ }^{9-11}$

Alarmingly, published studies also indicate shortcomings in the monitoring and identification of nonadherent patients. Studies aimed at identifying patients who are nonadherent and assessing patients' expectations concerning treatment may be helpful in developing effective treatment plans. ${ }^{12}$ Adherence-measurement methods can be broadly defined in two categories: direct and indirect. Direct methods include electronic monitoring systems, pill counting, medicationuse measurement, measurement of drug concentrations in bodily fluids, and measurement of serum activity of selected biochemical markers present in the medication. ${ }^{13}$ Indirect observation methods commonly include subjective measures, such as self-reported questionnaires and scales. Apart from pharmaceutical adherence, many of these methods also help identify difficulties in medication taking, patients' beliefs and attitudes toward the treatment, or their knowledge on the disease and its treatment. ${ }^{14}$

There has been research on adherence for 50 years, but there is still no gold standard or an optimal questionnaire allowing for simple screening in daily clinical practice, nor do standard criteria exist for selecting such a questionnaire. More than a dozen questionnaires on the subject are available in medical databases, but only a few have been validated in a population of chronically ill patients. ${ }^{15}$

The most commonly used questionnaires, especially in groups of patients with hypertension, include the Morisky Medication Adherence Scale (MMAS-8) ${ }^{16,17}$ and the HillBone Compliance Scale. ${ }^{18}$ Both instruments have been adapted into Polish. ${ }^{19,20}$ Due to the difficulty in accessing the MMAS-8 questionnaire and the high price of its license, the literature was reviewed, and the Adherence to Refills and Medications Scale (ARMS) questionnaire proved to be a simple and useful tool for adherence measurement with acceptable psychometric properties. Currently, the scale is available in multiple languages and is described as a simple, yet sensitive diagnostic instrument. ${ }^{21-23}$ Though Polish versions of the questionnaires exist, there is still no simple instrument for testing pharmaceutical adherence among chronically ill patients in daily practice that would enable the identification of patients at risk of nonadherence, especially in hypertensive populations.

\section{Aim of the study}

The aim of the study was to develop a Polish version of the ARMS (ARMS-P), an instrument that identifies levels of adherence in the hypertensive population, and evaluate its psychometric properties.

\section{Methods Study participants}

This cross-sectional study included 279 patients (of whom 166 were female) with a mean age of $66.5 \pm 11.0$ years hospitalized in the Department of Internal Medicine, Occupational Diseases, and Hypertension of Wrocław Medical University, Poland. The study was performed between September 2016 and March 2017 and was carried out by trained nurses at patient admission. Patient classification was performed by a trained physician, a specialist in internal medicine. Sociodemographic and clinical data were obtained from hospital records. Participation in the study was anonymous and voluntary. Each patient provided written consent to participate in the study and was informed that they could withdraw from the study at any stage.

\section{Inclusion and exclusion criteria}

Patients were included in the study if they had been diagnosed with hypertension in accordance with the European Society of Hypertension guidelines (BP value the mean of 
two measurements with an interval of 1-2 minutes; third measurement was done in patients whose difference in measurements was $>10 \mathrm{mmHg}$ ), had been treated with at least one antihypertensive drug for 6 months or more, were older than 18 years, and had no mental disorders or cognitive impairment with dementia. Patients were excluded from the study if they had limited cognitive function (score showing cognitive impairment with dementia on the Mini-Mental State Examination, cutoff at 23 points), did not provide informed consent in writing, or had an exacerbation of concurrent severe chronic diseases (cancer, respiratory failure, or cardiac decompensation).

\section{Ethical considerations}

The study was approved by the Bioethics Committee of Wrocław Medical University (approval KB-226/2016). The study was performed in accordance with the Helsinki Declaration and the principles of good clinical practice, with respect for the rights and dignity of the participants. All participants provided written informed consent.

\section{Questionnaire}

The ARMS was developed by Kripalani et al and tested among patients with coronary artery disease and other chronic conditions, including hypertension, dyslipidemia, and diabetes mellitus. Its initial version was developed based on the Morisky and Hill-Bone questionnaires. The 12 items included in the final questionnaire comprise two subscales: adherence to taking medications (eight items) and adherence to refilling prescriptions (four items). Each item was structured for response on a Likert scale with responses of "none", "some", "most", or "all" the time, which were given values from 1 to 4 . Most items were written so that lower scores indicated better adherence. Item scores are summed to produce an overall adherence score of 12-48, with lower scores indicating better adherence. ${ }^{21}$

\section{Translation procedures}

Within the project, the original version of the questionnaire was translated into Polish, and the psychometric properties of the ARMS-P were evaluated. Consistency in scale scores was calculated using Cronbach's $\alpha$. In addition, ANOVA and multivariate regression analysis were used to find predictors that significantly affected adherence. The 12-item ARMS was translated from English into Polish, then back-translated to test the accuracy of translation. ${ }^{24}$

Permission for translation was obtained in 2016 from the original developer of the English version of the
ARMS. The translation proceeded as follows: 1) forward translation - two bilingual people (a nurse and a public health specialist) independently translated the instrument from English to Polish without any mutual consultation; 2) back-translation - a bilingual nurse blinded to the original English version of the instrument back-translated the instrument from Polish to English; and 3) decentering - both the original English version and the translated Polish version of the instrument were deemed to be equally important for verifying that scale items in different language versions closely resembled each other. ${ }^{21}$

The translations received were reviewed by the research team, and all differences were discussed and reconciled. A draft instrument was then produced. The version produced by back-translation was sent to the author of the original ARMS questionnaire for approval. ${ }^{21}$ Following the author's approval of the translation, a pilot study was performed to verify patients' understanding of the Polish version of the questionnaire. This pilot study included 20 patients hospitalized due to hypertension in the Department of Internal Medicine, Occupational Diseases, and Hypertension of Wrocław Medical University, Poland. All patients completed the questionnaire on their own, and reported no difficulties in understanding or responding to any of the items. The pretested version of the ARMS-12 was used as the final version for psychometric testing in a population of hypertensive Polish patients.

\section{Statistical analysis}

Quantitative characteristics of the study group are shown in tables as mean $\pm \mathrm{SD}$, and nominal characteristics as numbers and percentages. ARMS homogeneity and validity was assessed using item-total correlations, Cronbach's $\alpha$, and confirmatory factor analysis with a Varimax-rotated component matrix. Goodness of fit was evaluated by calculating $\chi^{2}$, root mean square error of approximation, goodnessof-fit index, Tucker-Lewis index, confirmatory fit index, and normed-fit index. Analyses were performed using the Statistica version 13 software package (StatSoft) and the Sepath module.

\section{Results Participant characteristics}

A total of 290 patients were invited into the study, but 11 declined to participate. In the group of 279 patients, $66.5 \%$ were female and the mean age was 66.5 years. Participants' general and medication-related characteristics are shown in Table 1. 
Table I Sociodemographic characteristics of participants $(n=279)$

\begin{tabular}{|c|c|}
\hline Female sex, n (\%) & $166(59.5)$ \\
\hline Age (years), mean $\pm S D$ & $66.5 \pm 11.0$ \\
\hline$<65$ years, $\mathrm{n}(\%)$ & $153(54.8)$ \\
\hline Caucasian race, $\mathrm{n}(\%)$ & $279(100.0)$ \\
\hline \multicolumn{2}{|l|}{ Relationship status, n (\%) } \\
\hline In a relationship & $185(66.3)$ \\
\hline Single & $94(33.7)$ \\
\hline \multicolumn{2}{|l|}{ Residence, n (\%) } \\
\hline Rural & $85(30.5)$ \\
\hline Urban & $194(69.5)$ \\
\hline Professionally active, $\mathrm{n}(\%)$ & $100(35.8)$ \\
\hline \multicolumn{2}{|l|}{ Education, $\mathrm{n}(\%)$} \\
\hline None or primary & $55(19.7)$ \\
\hline High school & $96(34.4)$ \\
\hline College/university & $128(45.9)$ \\
\hline \multicolumn{2}{|l|}{ Blood pressure (mmHg), n (\%) } \\
\hline$\leq 140-159 / 90-99$ & $193(69.2)$ \\
\hline $160-179 / 100-109$ & $60(21.5)$ \\
\hline$\geq 180 / 110$ & $26(9.3)$ \\
\hline \multicolumn{2}{|c|}{ Frequency of blood-pressure measurement, n (\%) } \\
\hline One to three times a day & $\mid 43(5 \mid .3)$ \\
\hline More than once per week & $68(24.4)$ \\
\hline Once per week & II (3.9) \\
\hline When feeling worse & $35(12.5)$ \\
\hline At the physician's office & $22(7.9)$ \\
\hline \multicolumn{2}{|c|}{ Patient able to tell how many pills they take daily, $\mathrm{n}(\%)$} \\
\hline Yes, five or fewer & $98(35.1)$ \\
\hline Yes, more than five & $18(6.5)$ \\
\hline No & $163(58.4)$ \\
\hline \multicolumn{2}{|l|}{ How medication is taken, $\mathrm{n}(\%)$} \\
\hline Prepared and given by another person & $92(33.0)$ \\
\hline Prepared and taken by the patient & $187(67.0)$ \\
\hline \multicolumn{2}{|c|}{$\begin{array}{l}\text { Patient reads information leaflets for the prescribed } \\
\text { medication, } n(\%)\end{array}$} \\
\hline Yes, always & $88(31.5)$ \\
\hline Yes, sometimes & $85(30.5)$ \\
\hline Never & $106(38.0)$ \\
\hline
\end{tabular}

Table 2 shows reliability-analysis results for the ARMS-P questionnaire. Item-total correlation coefficients for the ARMS-P ranged between 0.363 and 0.891 (mean 0.670).

Table 3 shows reliability analysis for each ARMS-12 item (1-12), broken down by adherence categories: poor $(n=135)$ and good $(n=144)$. Mean scores for the pooradherence group ranged between $2.8 \pm 1.1$ and $1.7 \pm 0.9$ and for the good-adherence group between $1.8 \pm 1.1$ and $1.0 \pm 0$. The results showed good internal consistency.

The next stage involved analyzing patients' sociodemographic characteristics in the two adherence categories. Patients in the good-adherence group were younger $(P=0.017$; $P=0.048)$, more likely to be professionally active $(P=0.041)$, better educated $(P=0.037)$, and more likely to have normal BP values $(P<0.001)$. They also measured their BP more often $(P<0.001)$, and took fewer pills a day $(P<0.001)$. Adherent patients were also more likely to take their medication on their own $(P=0.016)$ and read information leaflets for the medication $(P<0.001)$. The data are shown in Table 4 .

Table 5 presents reduced factor analysis, with a forced two-factor solution for the ARMS-12 questionnaire Factor 1 has an eigenvalue of 6.672 and accounts for $55.6 \%$ of variance. It comprises ten items describing adherence to medication taking. Factor 2 (items 7 and 9) has an eigenvalue of 2.694 and accounts for $22.4 \%$ of variance. It comprises two items describing patients' tendency to change medication dosages arbitrarily.

In the adherence assessment $(\mathrm{n}=279)$, the mean score was $19.7 \pm 8.8(12-48)$ points. In the ARMS-12 reliability analysis, standardized Cronbach's $\alpha$ was 0.954 . The internal consistency of the ARMS was high, both for

Table 2 Reliability analysis for ARMS- 12 items in the study group $(n=279)$

\begin{tabular}{|c|c|c|c|}
\hline Question* & $\begin{array}{l}\text { Participants scores } \\
\text { (mean } \pm \text { SD) }\end{array}$ & $\begin{array}{l}\text { Item-total } \\
\text { correlation }\end{array}$ & $\begin{array}{l}\text { Cronbach's } \alpha \\
\text { if item removed }\end{array}$ \\
\hline I. How often do you forget to take your medicine? & 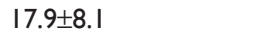 & 0.807 & 0.944 \\
\hline 2. How often do you decide not to take your medicine? & $18.2 \pm 8.1$ & 0.866 & 0.943 \\
\hline 3. How often do you forget to get prescriptions for your medicine? & $18.2 \pm 8.1$ & 0.875 & 0.942 \\
\hline 4. How often do you run out of medicine? & $18.2 \pm 8.1$ & 0.851 & 0.943 \\
\hline 5. How often do you skip a dose of your medicine before you go to the doctor? & $18.1 \pm 8.0$ & 0.886 & 0.942 \\
\hline 6. How often do you miss taking your medicine when you feel better? & $18.0 \pm 7.9$ & 0.877 & 0.942 \\
\hline 7. How often do you miss taking your medicine when you feel worse? & $18.3 \pm 8.2$ & 0.640 & 0.950 \\
\hline 8. How often do you miss taking your medicine when you are careless? & $18.1 \pm 8.1$ & 0.889 & 0.942 \\
\hline 9. How often do you change the dose of your medicine to suit your needs? & $18.4 \pm 8.4$ & 0.556 & 0.952 \\
\hline $\begin{array}{l}\text { 10. How often do you forget to take your medicine when you are supposed } \\
\text { to take it more than once a day? }\end{array}$ & $|8| \pm 8.0$. & 0.891 & 0.942 \\
\hline II. How often do you put off refilling your medicines because they cost too much money? & $18.1 \pm 8.0$ & 0.812 & 0.944 \\
\hline 12. How often do you plan ahead and refill your medicines before they run out?** & $17.5 \pm 8.3$ & 0.363 & 0.962 \\
\hline
\end{tabular}

Notes: $* *$ Questions reproduced with permission from Kripalani S, Risser J, Gatti ME, Jacobson TA. Development and evaluation of the Adherence to Refills and Medications Scale (ARMS) among low-literacy patients with chronic disease. Value Health. 2009;12(I):I I8-123. Copyright $\odot 2009$ Emory University. ${ }^{21} *$ This item was reverse-coded, ie, I = always, 2 =most of the time, 3 = sometimes, 4 = never.

Abbreviation: ARMS, Adherence to Refills and Medications Scale. 
Table 3 Reliability analysis for individual ARMS-P items in the study group $(n=279)$

\begin{tabular}{|c|c|c|}
\hline \multirow[t]{2}{*}{ Question* } & \multicolumn{2}{|l|}{ Adherence } \\
\hline & $\begin{array}{l}\text { Low }(16-48 \text { points }) \\
n=135 \text {, mean } \pm \text { SD }\end{array}$ & $\begin{array}{l}\text { High (8-15 points), } \\
n=144, \text { mean } \pm S D\end{array}$ \\
\hline I. How often do you forget to take your medicine? & $2.4 \pm 0.8$ & $1.3 \pm 0.5$ \\
\hline 2. How often do you decide not to take your medicine? & $2.1 \pm 0.9$ & $1.0 \pm 0.1$ \\
\hline 3. How often do you forget to get prescriptions for your medicine? & $2.1 \pm 1.0$ & $1.0 \pm 0.1$ \\
\hline 4. How often do you run out of medicine? & $2.1 \pm 0.9$ & $1.0 \pm 0.1$ \\
\hline 5. How often do you skip a dose of your medicine before you go to the doctor? & $2.3 \pm 0.9$ & $1.0 \pm 0.0$ \\
\hline 6. How often do you miss taking you medicine when you feel better? & $2.4 \pm 1.1$ & $1.0 \pm 0.1$ \\
\hline 7. How often do you miss taking your medicine when you feel worse? & $2.0 \pm 1.1$ & $1.0 \pm 0.0$ \\
\hline 8. How often do you miss taking your medicine when you are careless? & $2.2 \pm 0.9$ & $1.0 \pm 0.2$ \\
\hline 9. How often do you change the dose of your medicines to suit your needs? & $1.7 \pm 0.9$ & $1.0 \pm 0.1$ \\
\hline $\begin{array}{l}\text { 10. How often do you forget to take your medicine when you are supposed to take it } \\
\text { more than once a day? }\end{array}$ & $2.3 \pm 0.9$ & $1.0 \pm 0.2$ \\
\hline II. How often do you put off refilling your medicines because they cost too much money? & $2.1 \pm 1.1$ & $1.1 \pm 0.3$ \\
\hline 12. How often do you plan ahead and refill your medicines before they run out? & $2.8 \pm 1.1$ & $1.8 \pm 1.1$ \\
\hline
\end{tabular}

Notes: *Questions reproduced with permission from Kripalani S, Risser J, Gatti ME, Jacobson TA. Development and evaluation of the Adherence to Refills and Medications Scale (ARMS) among low-literacy patients with chronic disease. Value Health. 2009; 12(1): 1 18-123. Copyright (C) 2009 Emory University. ${ }^{21}$

Abbreviation: ARMS-P, Adherence to Refills and Medications Scale - Polish.

Table 4 Sociodemographic characteristics of the patients $(n=279)$ broken down by adherence and significance levels

\begin{tabular}{|c|c|c|c|}
\hline \multirow[t]{2}{*}{ Variable } & \multicolumn{2}{|c|}{ Adherence score (ARMS) } & \multirow[t]{2}{*}{$P$-value } \\
\hline & Low & High & \\
\hline Female sex, n (\%) & $74(54.8)$ & $92(63.9)$ & 0.123 \\
\hline Age (years), mean $\pm S D$ & $68.2 \pm 11.0$ & $65.0 \pm 10.7$ & 0.017 \\
\hline$<65$ years, $\mathrm{n}(\%)$ & $48(35.6)$ & $68(47.2)$ & 0.048 \\
\hline Caucasian race, n (\%) & $135(100.0)$ & $144(100.0)$ & 1.000 \\
\hline \multicolumn{4}{|l|}{ Relationship status, n (\%) } \\
\hline In a relationship & $87(64.4)$ & $98(68.1)$ & 0.524 \\
\hline Single & $48(35.6)$ & $46(31.9)$ & \\
\hline \multicolumn{4}{|l|}{ Residence, $\mathrm{n}(\%)$} \\
\hline Rural & $36(26.7)$ & $49(34.0)$ & 0.182 \\
\hline Urban & $99(73.3)$ & $95(66.0)$ & \\
\hline Professionally active, n (\%) & $39(28.9)$ & $61(42.4)$ & 0.041 \\
\hline \multicolumn{4}{|l|}{ Education, $\mathrm{n}(\%)$} \\
\hline None or primary & $33(24.5)$ & $22(15.3)$ & 0.037 \\
\hline High school & $50(37.0)$ & $46(31.9)$ & \\
\hline College/university & $52(38.5)$ & $76(52.8)$ & \\
\hline \multicolumn{4}{|l|}{ Blood pressure $(\mathrm{mmHg}), \mathrm{n}(\%)$} \\
\hline Normal $(\leq 140 / 90)$ & $62(45.9)$ & |3| (9|.0) & $<0.00 \mathrm{I}$ \\
\hline High $(\geq 140 / 90)$ & $73(54.1)$ & $13(9.0)$ & \\
\hline \multicolumn{4}{|c|}{ Frequency of blood-pressure measurement, n (\%) } \\
\hline One to three times a day & $52(38.5)$ & $91(63.2)$ & $<0.001$ \\
\hline More than once per week & $29(21.5)$ & $39(27.1)$ & \\
\hline Once per week & $9(6.7)$ & $2(1.4)$ & \\
\hline When feeling worse & $28(20.7)$ & $7(4.9)$ & \\
\hline At the physician's office & $17(2.6)$ & $5(3.5)$ & \\
\hline \multicolumn{4}{|c|}{ Patient able to tell how many pills they take daily, $\mathrm{n}(\%)$} \\
\hline Yes, five or fewer & $31(23.0)$ & $67(46.5)$ & $<0.001$ \\
\hline Yes, more than five & $14(10.4)$ & $4(2.8)$ & \\
\hline No & $90(66.6)$ & $73(50.7)$ & \\
\hline \multicolumn{4}{|l|}{ How medication is taken, $\mathrm{n}(\%)$} \\
\hline Prepared and given by another person & $54(40.0)$ & $38(26.4)$ & 0.016 \\
\hline Prepared and taken by the patient & $81(60.0)$ & $106(73.6)$ & \\
\hline \multicolumn{4}{|c|}{ Patient reads information leaflets for the prescribed medication, $\mathrm{n}(\%)$} \\
\hline Yes, always & $19(14.1)$ & $69(47.9)$ & $<0.001$ \\
\hline Yes, sometimes & $41(30.4)$ & $44(30.6)$ & \\
\hline Never & $75(55.6)$ & $31(21.5)$ & \\
\hline
\end{tabular}


Table 5 Factor analysis (varimax-rotated component matrix) for ARMS in the study group $(n=279)$

\begin{tabular}{l|l|l}
\hline Question* & Factor I & Factor $\mathbf{2}$ \\
\hline I. How often do you forget to take your medicine? & 0.797 & 0.739 \\
2. How often do you decide not to take your medicine? & 0.879 \\
3. How often do you forget to get prescriptions for your medicine? & 0.878 \\
4. How often do you run out of medicine? & 0.775 \\
5. How often do you skip a dose of your medicine before you go to the doctor? & 0.745 \\
6. How often do you miss taking you medicine when you feel better? & 0.84 I \\
7. How often do you miss taking you medicine when you feel worse? & \multirow{2}{*}{0.746} \\
8. How often do you miss taking your medicine when you are careless? & 0.863 \\
9. How often do you change the dose of your medicines to suit your needs? & 0.823 \\
I0. How often do you forget to take your medicine when you are supposed to take it more than once a day? & 0.663 \\
II. How often do you put off refilling your medicines because they cost too much money? & 6.672 \\
I2. How often do you plan ahead and refill your medicines before they run out? & $55.6 \%$ \\
Eigenvalue & 2.694 \\
Variance accounted for & $22.4 \%$ \\
\hline
\end{tabular}

Notes: *Questions reproduced with permission from Kripalani S, Risser J, Gatti ME, Jacobson TA. Development and evaluation of the Adherence to Refills and Medications Scale (ARMS) among low-literacy patients with chronic disease. Value Health. 2009; 12(I): I 18-123. Copyright @ 2009 Emory University. ${ }^{21}$

Abbreviation: ARMS, Adherence to Refills and Medications Scale.

patients with no education or primary education only (Cronbach's $\alpha=0.948$ ) and for patients with high school $(\alpha=0.951)$ and college/university $(\alpha=0.960)$ education. All item-total correlation coefficients were $>0.3$, which also demonstrates good internal consistency regardless of patient education.

For domain (subscale) 1, Cronbach's $\alpha$ was 0.958 and item-total correlation coefficients $0.395-0.897$. For domain 2 , item-total correlation was 0.632 and Cronbach's $\alpha 0.775$. The internal consistency of ARMS items was high both for patients with normal BP $(\alpha=0.950)$ and those with high BP $(\alpha=0.936)$. All item-total correlation coefficients were $>0.3$, which demonstrates good internal consistency regardless of patient BP values. The data are shown in Table 6.

At the final stage of analysis, criterion validity of the ARMS-12 questionnaire was evaluated in relation to

Table 6 Adherence scores for the studied group $(n=279)$ in the entire ARMS scale and its domains, with scale internal consistency analysis

\begin{tabular}{|c|c|c|c|c|c|c|c|c|c|}
\hline \multirow[t]{3}{*}{ Group (n) } & \multicolumn{9}{|c|}{ ARMS- 12 reliability analysis } \\
\hline & \multicolumn{3}{|l|}{ ARMS global } & \multicolumn{3}{|l|}{ Domain I } & \multicolumn{3}{|l|}{ Domain 2} \\
\hline & $\begin{array}{l}\text { Participants } \\
\text { scores } \\
\text { (mean } \pm \text { SD) }\end{array}$ & $\alpha$ & $r$ & $\begin{array}{l}\text { Participants } \\
\text { scores } \\
\text { (mean } \pm \text { SD) }\end{array}$ & $\alpha$ & $r$ & $\begin{array}{l}\text { Participants } \\
\text { scores } \\
\text { (mean } \pm \text { SD) }\end{array}$ & $\alpha$ & $r$ \\
\hline Total (279) & $19.7 \pm 8.8$ & 0.954 & 0.670 & $16.9 \pm 7.8$ & 0.958 & 0.729 & $2.8 \pm 1.5$ & 0.775 & 0.632 \\
\hline \multicolumn{10}{|l|}{ Sex } \\
\hline Female (I66) & $18.8 \pm 8.2$ & 0.952 & 0.660 & $16.1 \pm 7.3$ & 0.959 & 0.729 & $2.7 \pm 1.3$ & 0.735 & 0.581 \\
\hline Male (II3) & $21.1 \pm 9.6$ & 0.955 & 0.677 & $18.1 \pm 8.3$ & 0.957 & 0.727 & $3.0 \pm 1.7$ & 0.810 & 0.681 \\
\hline \multicolumn{10}{|l|}{ Age (years) } \\
\hline$\leq 65(126)$ & $19.3 \pm 9.1$ & 0.963 & 0.724 & $16.6 \pm 8.0$ & 0.967 & 0.780 & $2.8 \pm 1.6$ & 0.840 & 0.724 \\
\hline$>65(153)$ & $20.1 \pm 8.6$ & 0.946 & 0.631 & $17.2 \pm 7.6$ & 0.951 & 0.694 & $2.9 \pm 1.5$ & 0.712 & 0.552 \\
\hline \multicolumn{10}{|l|}{ Residence } \\
\hline Rural (85) & $19.8 \pm 9.4$ & 0.965 & 0.727 & $16.9 \pm 8.3$ & 0.972 & 0.790 & $2.9 \pm 1.5$ & 0.690 & 0.527 \\
\hline Urban (194) & $19.7 \pm 8.6$ & 0.949 & 0.654 & $16.9 \pm 7.6$ & 0.953 & 0.712 & $2.8 \pm 1.5$ & 0.830 & 0.710 \\
\hline \multicolumn{10}{|l|}{ Relationship status } \\
\hline Single (94) & $19.8 \pm 8.7$ & 0.949 & 0.653 & $16.9 \pm 7.6$ & 0.953 & 0.709 & $2.9 \pm 1.6$ & 0.759 & 0.612 \\
\hline In a relationship (185) & $19.7 \pm 8.9$ & 0.956 & 0.684 & $16.9 \pm 7.9$ & 0.961 & 0.745 & $2.8 \pm 1.5$ & 0.783 & 0.644 \\
\hline \multicolumn{10}{|l|}{ Professional activity } \\
\hline Active $(100)$ & $19.7 \pm 9.4$ & 0.965 & 0.738 & $17.0 \pm 8.4$ & 0.973 & 0.807 & $2.7 \pm 1.5$ & $0.78 \mathrm{I}$ & 0.641 \\
\hline Not active (178) & $19.7 \pm 8.5$ & 0.947 & 0.638 & $16.8 \pm 7.4$ & 0.948 & 0.685 & $2.9 \pm 1.5$ & 0.785 & 0.647 \\
\hline \multicolumn{10}{|l|}{ Education } \\
\hline Primary $(55)$ & $22.4 \pm 9.5$ & 0.948 & 0.652 & $19.6 \pm 8.8$ & 0.965 & 0.752 & $2.8 \pm 1.4$ & 0.561 & 0.390 \\
\hline High school/college/university (224) & $19.1 \pm 8.6$ & 0.955 & 0.677 & $16.2 \pm 7.4$ & 0.955 & 0.720 & $2.8 \pm 1.5$ & 0.820 & 0.693 \\
\hline
\end{tabular}

Notes: Domain I, adherence to medication taking; domain 2, tendency to change medication dosage arbitrarily.

Abbreviation: ARMS, Adherence to Refills and Medications Scale. 
Table 7 Relationship between adherence scores and BP control groups

\begin{tabular}{l|l|l|l}
\hline \multirow{2}{*}{$\begin{array}{l}\text { Adherence } \\
\text { level (ARMS) }\end{array}$} & \multicolumn{2}{|l|}{ BP control } & $\begin{array}{l}\text { Fisher's exact } \\
\text { test (P-value) }\end{array}$ \\
\cline { 2 - 3 } & Yes, $\mathbf{n}(\%)$ & No, $\mathbf{n}(\%)$ & \\
\hline Poor $(>12)$ & $173(89.6)$ & $86(100.0)$ & $<0.001$ \\
Good $(\leq 12)$ & $20(10.4)$ & 0 & \\
\hline
\end{tabular}

Abbreviations: BP, blood pressure; ARMS, Adherence to Refills and Medications Scale.

adherence scores and BP control. In the poor-adherence group, BP was uncontrolled in more patients than in the goodadherence group (100\% vs $0 \%$ ). Table 7 shows the distribution of adherence scores in relation to proper BP control.

The diagnostic capability of the ARMS-P was tested against BP criteria (gold standard). Comparison of the sums of ARMS questionnaire points with the gold standard showed four possible interpretations could emerge: true positive, when the ARMS result and BP criteria are positive; false positive, when the ARMS result is positive and BP negative; false negative, when the ARMS result is negative and BP positive; and true negative, when the ARMS result and BP are negative. Two-by-two tables were constructed with these data. From these comparative interpretations, sensitivity and specificity values were calculated. Sums of ARMS questionnaire points $\leq 15$ showed sensitivity $78.2 \%$, specificity $80.2 \%$, and AUC 0.816 .

\section{Discussion}

The ARMS was developed to evaluate self-reported adherence to taking and refilling medications among chronically ill patients. ${ }^{12}$ To our knowledge, the ARMS-12 is one of the best questionnaires for studying adherence in hypertensive patients, and also for elderly patients (mean age 71 years). ${ }^{21}$ Importantly, it can be administered at no additional cost. Adherence to prescribed pharmaceutical treatment is a prerequisite for effective treatment of hypertension. Nonadherence may adversely affect patient health and contribute to a number of complications and even death, hence the need for routine adherence testing in this population.

The purpose of the present study was to develop a Polish version of the ARMS-12 questionnaire and to evaluate its psychometric properties. The study was performed in a population of hypertensive patients, and demonstrated that the ARMS-P questionnaire has good psychometric properties that enable its use for assessing adherence in chronically ill patients, including in particular patients with hypertension.

Validation was based on determining a routine psychometric characteristic, Cronbach's $\alpha$, which measured the instrument's internal consistency. Psychometric analyses revealed high internal consistency, reliability, and criterion validity. The internal consistency of the Polish ARMS-12 was 0.954. The calculated item-total correlation coefficients for ARMS-P ranged between 0.363 and 0.891 (mean 0.670). The present results demonstrate that the ARMS-P has excellent psychometric properties, better than those found for the original version of the questionnaire $(r=0.814)$ or for other validated language versions, eg, Korean (0.801). ${ }^{22}$

As in the original version of the questionnaire, factor analysis for construct validity identified two factors in the present study. ${ }^{21}$ Factor 1 had an eigenvalue of 6.672 and accounted for $55.6 \%$ of variance. It comprises ten items describing adherence to medication taking. Factor 2 had an eigenvalue of 2.694 and accounted for $22.4 \%$ of variance. It comprises two items describing patients' tendency to change medication dosages arbitrarily.

In the validation study of the original version, the authors initially applied a three-factor solution, which accounted for $47.9 \%$ of variance, forcing a two-factor solution in the final version, which according to the authors did not produce a clear separation of the items as intended in the instrument design. In the two-factor analysis, factor 1 accounted for $35.1 \%$ and factor $210 \%$ of variance. In the validation study of the Korean version, performed in a group of patients with type 2 diabetes, a three-factor solution was also used. Cronbach's $\alpha$ for factor 1 (refilling medicine and intentional nonadherence) was 0.736 , for factor 2 (unintentional nonadherence with taking nonadherence) 0.747 , and for factor 3 (persistence with refilling medicine) 0.603 .

In the present study, Cronbach's $\alpha$ for domain 1 (adherence to medication taking) was 0.958 , and item-total correlation coefficients $0.395-0.897$. For domain 2 , the item-total correlation coefficient was 0.632 and Cronbach's $\alpha 0.775$. The values found for the ARMS-P are higher than those for the original version (factor $1, \alpha=0.794$; factor $2, \alpha=0.641$ ). All item-total correlation coefficients were $>0.3$, which also demonstrates good internal consistency, regardless of patient education. In their study, Kripalani et al emphasized that the ARMS was the first questionnaire with suitability for use in patients with limited literacy skills. They furthermore believed that the ARMS allowed for valid and reliable assessment in patients with all literacy levels, and also when its items were presented verbally. ${ }^{21}$ Notably, in studies on adherence, health literacy is considered a significant factor limiting adherence to treatment. ${ }^{25}$

Understanding of causes of poor adherence contributes to making decisions and planning targeted interventions, and is key in decreasing morbidity and mortality. ${ }^{26}$ Among the factors affecting adherence, the role of sociodemographic 
predictors is often discussed. In the present study, comparative analysis demonstrated that nonadherent patients were older, less educated, and less likely to be professionally active. Literature on the subject corroborates the present findings, though the discussion on associations between age and adherence is ongoing. ${ }^{27-29}$

The impact of cognitive impairment and mental limitations on adherence has also been emphasized in many publications. ${ }^{30}$ Concurrent cognitive impairment in elderly patients is associated with worse perception of health, increased number of comorbidities, and social isolation of the patient. ${ }^{31}$ It can also be suspected to interfere with treatment adherence. ${ }^{32}$ Few studies are available on the association between the components of geriatric syndrome and adherence to treatment. Those papers that have discussed associations between frailty and adherence were based on populations with diseases other than hypertension. ${ }^{30,33}$ There is also a discussion in the available literature regarding the impact of frailty syndrome on adherence. . $^{34,35}$

Available studies place much emphasis on the association between adherence and knowledge, with authors reporting that knowledge and education are considered crucial for proper hypertension control. ${ }^{36-39}$ The authors of the original ARMS questionnaire included low-literacy patients in their study, demonstrating, similar to the present study, that the AMS is a valid and reliable medication-adherence scale in a population of chronically ill patients with limited health literacy. ${ }^{38}$

In the present study, the internal consistency of the ARMS was high, both for patients with no education or primary education only $(\alpha=0.948)$ and for patients with high school $(\alpha=0.951)$ and college/university $(\alpha=0.960)$ education. All item-total correlation coefficients were $>0.3$, which also demonstrates good internal consistency, regardless of patient education.

Several aspects of the present analysis support the validity of the ARMS. It correlates strongly with hypertension control: better adherence scores are associated with better BP control. In the present study, patients in the good-adherence group were more likely to check their BP regularly, while patients in the low-adherence group were significantly more inclined to check their BP only when they felt worse. Similarly, BP values were more often normal in the good-adherence group and high in the poor-adherence group. Kripalani et al also reported a significant association between adherence, diastolic BP control, and overall BP control, providing evidence of validity for the overall scale, though possibly indicating the importance of factors other than medication adherence (eg, diet and lifestyle) in the control of BP. ${ }^{21,26,38}$
Therefore, the ARMS-P questionnaire can be considered an instrument with good psychometric properties. A reliable and valid adherence measurement based on patient self-reporting may be helpful in daily practice.

\section{Limitations}

One limitation of this study is that it was carried out at a single inner-city hospital. Second, most patients in the study used five or more medications daily, and the scale may perform differently in populations with less medication use. Another limitation is the lack of a repeatability (retest) analysis, as well as the lack of a comparison between the self-reported adherence measure and biochemical measures that could corroborate it, or a comparison with another instrument with confirmed good psychometric properties in the Polish setting. An evaluation of health behaviors should be performed alongside the adherence measurement, as health behaviors are as significant in hypertension treatment as medication. Future research will need to assess the scale's performance in other settings, as well as its ability to measure changes that might result from interventions to enhance adherence.

\section{Conclusion}

The psychometric properties of the questionnaire are satisfactory (test reliability measured with Cronbach's $\alpha$ ). The ARMS-P questionnaire proved to be suitable for use in the Polish population. The use of this screening tool for assessment of adherence to treatment is recommended in hypertensive patients. Further studies are warranted in Polish populations of patients with other chronic diseases, in order to evaluate the psychometric properties of the ARMS-P questionnaire and to identify nonadherent patients, enabling the planning of therapeutic interventions.

\section{Acknowledgments}

The authors would like to thank the authors of the original ARMS questionnaire and all the patients who agreed to participate in our study. This study was performed within a project of Wrocław Medical University: ST.E020.17.050.

\section{Disclosure}

The authors report no conflicts of interest in this work.

\section{References}

1. Abegaz TM, Shehab A, Gebreyohannes EA, Bhagavathula AS, Elnour AA. Nonadherence to antihypertensive drugs: A systematic review and metaanalysis. Medicine (Baltimore). 2017;96(4):e5641.

2. Durand H, Hayes P, Morrissey EC, et al. Medication adherence among patients with apparent treatment-resistant hypertension: systematic review and meta-analysis. J Hypertens. 2017;35(12):2346-2357. 
3. Vrijens B, de Geest S, Hughes DA, et al; ABC Project Team. A new taxonomy for describing and defining adherence to medications. $\mathrm{Br} \mathrm{J}$ Clin Pharmacol. 2012;73(5):691-705.

4. Wetzels GE, Nelemans P, Schouten JS, Prins MH. Facts and fiction of poor compliance as a cause of inadequate blood pressure control: a systematic review. J Hypertens. 2004;22(10):1849-1855.

5. Osterberg L, Blaschke T. Adherence to medication. N Engl J Med. 2005; 353(5):487-497.

6. Gehi AK, Ali S, Na B, Whooley MA. Self-reported medication adherence and cardiovascular events in patients with stable coronary heart disease: the heart and soul study. Arch Intern Med. 2007;167(16): 1798-1803.

7. Zdrojewski T, Wyrzykowski B, Szczęch R, et al; Steering Committees of the Programmes NATPOL PLUS; SMS; Polish 400-Cities Project. Epidemiology and prevention of arterial hypertension in Poland. Blood Press. 2005;14(suppl 2):10-16.

8. Gorczyca-Michta I, Wożakowska-Kapłon B. Leczenie nadciśnienia tętniczego u osób w podeszłym wieku. Folia Cardiol Exc. 2009;4: 279-280.

9. Wolf-Maier K, Cooper RS, Kramer H, et al. Hypertension treatment and control in five European countries, Canada, and the United States. Hypertension. 2004;43(1):10-17.

10. He W, Bonner A, Anderson D. Patient reported adherence to hypertension treatment: a revalidation study. Eur J Cardiovasc Nurs. 2016;15(2): $150-156$

11. Dimatteo MR, Giordani PJ, Lepper HS, Croghan TW. Patient adherence and medical treatment outcomes: a meta-analysis. Med Care. 2002; 40(9):794-811.

12. Wolf-Maier K, Cooper RS, Banegas JR, et al. Hypertension prevalence and blood pressure levels in 6 European countries, Canada, and the United States. JAMA. 2003;289(18):2363-2369.

13. Christensen A, Osterberg LG, Hansen EH. Electronic monitoring of patient adherence to oral antihypertensive medical treatment: a systematic review. J Hypertens. 2009;27(8):1540-1551.

14. The Word Health Report 2002: Reducing Risks, Promoting Healthy Life. Geneva: WHO; 2002.

15. Nguyen TM, La Caze A, Cottrell N. What are validated self-report adherence scales really measuring?: a systematic review. $\mathrm{Br} \mathrm{J}$ Clin Pharmacol. 2014;77(3):427-445.

16. Morisky DE, Ang A, Krousel-Wood M, Ward HJ. Predictive validity of a medication adherence measure in an outpatient setting. $J$ Clin Hypertens (Greenwich). 2008;10(5):348-354.

17. Morisky DE, Green LW, Levine DM. Concurrent and predictive validity of a self-reported measure of medication adherence. Med Care. 1986; 24(1):67-74.

18. Kim MT, Hill MN, Bone LR, Levine DM. Development and testing of the Hill-Bone compliance to high blood pressure therapy scale. Prog Cardiovasc Nurs. 2000;15(3):90-96.

19. Jankowska-PolańskaB,UchmanowiczI,ChudiakA,DudekK, Morisky DE, Szymańska-Chabowska A. Psychometric properties of the Polish version of the eight-item Morisky Medication Adherence Scale in hypertensive adults. Patient Prefer Adherence. 2016;10:1759-1766.

20. Uchmanowicz I, Jankowska-Polańska B, Chudiak A, SzymańskaChabowska A, Mazur G. Psychometric evaluation of the Polish adaptation of the Hill-Bone Compliance to High Blood Pressure Therapy Scale. BMC Cardiovasc Disord. 2016;16(1):6.

21. Kripalani S, Risser J, Gatti ME, Jacobson TA. Development and evaluation of the Adherence to Refills and Medications Scale (ARMS) among low-literacy patients with chronic disease. Value Health. 2009 12(1):118-123.

22. Kim CJ, Park E, Schlenk EA, Kim M, Kim DJ. Psychometric evaluation of a Korean version of the Adherence to Refills and Medications Scale (ARMS) in adults with type 2 diabetes. Diabetes Educ. 2016;42(2):188-198.
23. Gökdoğan F, Kes D. Validity and reliability of the Turkish Adherence to Refills and Medications Scale. Int J Nurs Pract. 2017;23(5):e12566.

24. Brislin RW. Back-translation for cross-cultural research. J Cross Cult Psychol. 1970;1(3):185-216.

25. Gazmararian JA, Kripalani S, Miller MJ, et al. Factors associated with medication refill adherence in cardiovascular-related diseases: a focus on health literacy. J Gen Intern Med. 2006;21(12):1215-1221.

26. Kripalani S, Yao X, Haynes RB. Interventions to enhance medication adherence in chronic medical conditions: a systematic review. Arch Intern Med. 2007;167(6):540-550.

27. Sabate E. Adherence to Long-Term Therapies: Evidence for Action. Geneva, Switzerland: World Health Organization; 2003. Available from: http://www.who.int/chp/knowledge/publications/adherence_ report/en/index.html. Accessed June 9, 2018.

28. Chen SL, Tsai JC, Chou KR. Illness perceptions and adherence to therapeutic regimens among patients with hypertension: a structural modeling approach. Int J Nurs Stud. 2011;48(2):235-245.

29. Jankowska-Polańska B, Blicharska K, Uchmanowicz I, Morisky DE. The influence of illness acceptance on the adherence to pharmacological and non-pharmacological therapy in patients with hypertension. Eur $J$ Cardiovasc Nurs. 2016;15(7):559-568.

30. Chao CT, Huang JW, COGENT (COhort of GEriatric Nephrology in NTUH) study group. Geriatric syndromes are potential determinants of the medication adherence status in prevalent dialysis patients. PeerJ. 2016;4:e2122.

31. Fried LP, Tangen CM, Walston J, et al; Cardiovascular Health Study Collaborative Research Group. Frailty in older adults: evidence for a phenotype. J Gerontol A Biol Sci Med Sci. 2001;56(3): M146-M157.

32. Corrao G, Rea F, Ghirardi A, et al. Adherence with antihypertensive drug therapy and the risk of heart failure in clinical practice. Hypertension. 2015;66(4):742-749.

33. Sheppard VB, Faul LA, Luta G, et al. Frailty and adherence to adjuvant hormonal therapy in older women with breast cancer: CALGB protocol 369901. J Clin Oncol. 2014;32(22):2318-2327.

34. Jankowska-Polańska B, Dudek K, Szymańska-Chabowska A, Uchmanowicz I. The influence of frailty syndrome on medication adherence among elderly patients with hypertension. Clin Interv Aging. 2016; 11:1781-1790.

35. Krousel-Wood M, Thomas S, Muntner P, Morisky D. Medication adherence: a key factor in achieving blood pressure control and good clinical outcomes in hypertensive patients. Curr Opin Cardiol. 2004;19(4):357-362.

36. Jankowska-Polańska B, Uchmanowicz I, Dudek K, Mazur G. Relationship between patients' knowledge and medication adherence among patients with hypertension. Patient Prefer Adherence. 2016;10:2437-2447.

37. Han HR, Chan K, Song H, Nguyen T, Lee JE, Kim MT. Development and evaluation of a hypertension knowledge test for Korean hypertensive patients. J Clin Hypertens (Greenwich). 2011;13(10):750-757.

38. Risser J, Jacobson TA, Kripalani S. Development and psychometric evaluation of the Self-efficacy for Appropriate Medication Use Scale (SEAMS) in low-literacy patients with chronic disease.JNurs Meas. 2007; 15(3):203-219.

39. Wolf MS, Chang CH, Davis T, Makoul G. Development and validation of the Communication and Attitudinal Self-Efficacy scale for cancer (CASE-cancer). Patient Educ Couns. 2005;57(3):333-341. 
Patient Preference and Adherence

Dovepress

\section{Publish your work in this journal}

Patient Preference and Adherence is an international, peer-reviewed, open access journal that focuses on the growing importance of patient preference and adherence throughout the therapeutic continuum. Patient satisfaction, acceptability, quality of life, compliance, persistence and their role in developing new therapeutic modalities and compounds to optimize

clinical outcomes for existing disease states are major areas of interest for the journal. This journal has been accepted for indexing on PubMed Central. The manuscript management system is completely online and includes a very quick and fair peer-review system, which is all easy to use. Visit http://www. dovepress.com/testimonials.php to read real quotes from published authors.

Submit your manuscript here: http://www.dovepress.com/patient-preference-and-adherence-journal 